\section{Global Journal of Information Technology: Emerging Technologies}

Volume 07, Issue 1, (2017) 196-205

\title{
Exploring the use of social networking tools among Lebanese students
}

Rana Zein ", Department of Mathematics Education, Zayed University, 19282, Abu Dhabi, United Arab Emirates Hani Lababidi, Department of Medicine, King Fahed Medical City - CRESENT, 11525, Riyadh, Saudi Arabia Maysoun Dimashkieh, HAAD, 5674, Abu Dhabi, United Arab Emirates

\section{Suggested Citation:}

Zein, R., Lababidi, H. \& Dimashkieh, M. (2017). Exploring the use of social networking tools among Lebanese students Global Journal of Information Technology: Emerging Technologies. 7(1), 196-205.

Received November 21,2016; revised January 16, 2017; accepted April 10, 2017.

Selection and peer review under responsibility of Prof. Dr. Dogan Ibrahim, Near East University, Cyprus.

${ }^{\circledR} 2016$ SciencePark Research, Organization \& Counseling. All rights reserved.

\begin{abstract}
During the last decade, Social Networking (SN) tools have become increasingly popular and are now an important part of our daily lives. SN tools can be brought into the classroom to bear on some of the challenges the faculty face in enabling students to succeed in their education. This study explores various SN tools used by high school students in Lebanon. It gives insight into students' suggestions and ideas for various formal learning tasks using SN tools that might be beneficial for teaching and learning. Lebanese students were found to use SN applications in their daily lives extensively, for communication, socialization and various formats of formal and informal learning. The most widely used app was the WhatsApp Instant Messenger.
\end{abstract}

Keywords: social networking tools, formal learning, informal learning.

\footnotetext{
* ADDRESS FOR CORRESPONDENCE: Rana Zein, Zayed University, Abu Dhabi, United Arab Emirates

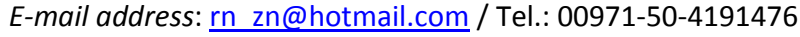


Zein, R., Lababidi, H. \& Dimashkieh, M. (2017). Exploring the use of social networking tools among Lebanese students Global Journal of Information Technology: Emerging Technologies. 7(1), 196-205

\section{Introduction}

As technology is altering our lives in a rapid way, students do not only seek out information from the web but also have the potential to communicate, share and produce information (Solomon \& Shrum, 2007). Social Networking (SN) tools are defined as a set of software applications that allow users to interact and collaborate together online (Leslie \& Landon, 2007). This study answers the following research questions:

1. How often and for what purposes do students use SN tools at home and at school?

2. Which type of formal learning activities do students prefer to implement with various SN tools?

\section{The Study and the Methodology}

This study was conducted among Lebanese students in grades from 10 to 12 . A questionnaire and two focus group interviews were administered in two urban high schools in Lebanon. The questionnaire was a modification of a survey developed initially by Saeed and Yang (Saeed \& Yang, 2008). The questionnaire was piloted on a group of five students and customized to fit the Lebanese students' language needs.

The aim of the questionnaire was to collect data on the students' use of SN tools, as well as their current knowledge and preferences. The questionnaire consisted of three sections; user's demographics, current uses of SN tools and user's learning preferences. The SN tools included in this study were; Blog, Wiki, Podcast /Vodcast (YouTube), Instant Messenger (WhatsApp Messenger), Facebook and E-mail.

The questionnaire utilized a combination of closed, open-ended and Likert scale questions. From the two hundred and fifteen students in the sample, only one hundred and twenty-five completed the questionnaire, a response rate of $58 \%$.

Frequency and numerical tables were generated to analyze which SN tools the students were using the most, their preferences for formal and informal learning tasks and their suggestions for future formal learning activities.

Qualitative data was also collected from two focus group interviews of five students each. The following semi-structured interview questions were discussed:

a. What are your current uses of SN tools in formal and informal learning?

b. What are the advantages and disadvantages of using $\mathrm{SN}$ tools in teaching and learning?

Why have you used certain tools over others in specific learning tasks? Explain your choice.

\section{Findings and Analysis of Findings}

\subsection{Research Question (1) "How often and for what purposes do students use SN tools at home and at school?"}

\subsubsection{Quantitative Research Findings: Results from the Survey Questionnaire}

One hundred and twenty-five students out of two hundred and fifteen students provided completed data. All the one hundred and twenty-five students surveyed had computers and Internet connections at home. All of them were using the Internet at home for at least 4 hours/week; $60 \%$ were using it from 5 to 25 hours/week, while $20 \%$ were using it for more than 25 hours/week. 
However, a big gap was found when comparing home-time to school-time Internet usage. All the students were found to use it for less than 4 hours/week at school. Moreover, $100 \%$ of the students used a desktop or laptop audio player; $72 \%$ had access to an audio player using a mobile phone and $50 \%$ were using tablets. These high percentages of audio player use present a potential for the future integration of podcasting and mobile technology (including mobiles, laptops and tablets) in teaching and learning. When asked about the SN tools mostly used, the students ranked WhatsApp Instant Messenger (IM) and WhatsApp Calls as their first choice; Skype, Viber and Tango as their $2^{\text {nd }}$ choice; Facebook as their $3^{\text {rd }}$ choice, whilst Wiki and Blogs were their last choice.

All students had experience of E-mail, Facebook, IM and Wiki. The highest percentages, and the oldest tools known by students for more than two years, were; E-mail (76\%), followed by Facebook (60\%) and IM (50\%); Blog, Wiki and Podcast/Vodcast were the newest tools to be used by the students. E-mail, Facebook and IM were used by all the students during the last two years. Students were less experienced in using Blog, Wiki, Podcast and Vodcast. Only $5 \%$ of the students surveyed didn't have any experience with Blogs.

There were variations in the frequencies and duration of time spent on different SN tools. IM and Facebook were the most frequently used, ranging from 1-3 hours/week to more than 10 hours/week. Blogs and Wikis were less frequently used at school, as compared to home. The majority of students noted using Blogs and Wikis for more than 1-2 hours/week. Blogs and Wikis were found to be used more at home than at school. Teachers in class formally used Blogs and Wikis, whilst the remaining tools were either not used by teachers (like Facebook or IM) or occasionally used as needed (like Email and Podcast/Vodcast).

The comparison of use between Blog and Wiki is presented in Table 1; the main uses were for group collaboration ( $56 \%$ for Wikis vs. $52 \%$ for Blogs), self-learning ( $56 \%$ for Wikis, vs. $54 \%$ for Blogs) and shared editing (44\% for Wikis vs. $40 \%$ for Blogs). These results show the importance of Blogs and Wikis, not only in individual self-learning but also for group collaboration.

Table 1. "Best features of Blog and Wiki “

\begin{tabular}{lllll}
\hline Blogs & & \multicolumn{3}{c}{ Wikis } \\
$\mathrm{N}$ & & $\%$ & $\mathrm{~N}$ & $\%$ \\
\hline a) Online journaling / personal blogging & 10 & 8 & 3 & 2 \\
b) shared editing & 50 & 40 & 55 & $\underline{44}$ \\
c) social contacts / socializing & 8 & 6 & 5 & 4 \\
d) group collaboration & 65 & $\underline{52}$ & 70 & $\underline{56}$ \\
e) ideas and information sharing & 43 & $\underline{34}$ & 45 & $\underline{36}$ \\
f) self-promotion /marketing yourself & 3 & 2 & & 0 \\
g) self-learning & 67 & $\underline{54}$ & 70 & $\underline{56}$ \\
h) other (please specify below) & & 0 & & 0 \\
Total & 246 & 196 & 248 & 198 \\
\hline
\end{tabular}

Survey Question: What is the best feature of Blogs and Wikis?

WhatsApp IM and Facebook were by far the most preferred means of social communication among students when compared to E-mail, Blogs and Wiki. Table 2 presents the comparison of SN purpose of use for the students surveyed. This illustrates the high interest in socialization behind the use of these tools and the ease of the audio/video/text formats in WhatsApp IM and Facebook, when compared to Email, Blog and Wiki.

The results emphasized the use of Blog and Wiki in promoting independent learning, as a selflearning tool; $57 \%$ and $58 \%$, in the first place, and as collaboration tools in the second place; $70 \%$ and $75 \%$, respectively. On the other hand, Facebook, WhatsApp IM and Email were used extensively in informal learning, through group collaboration and problem solving. 
Zein, R., Lababidi, H. \& Dimashkieh, M. (2017). Exploring the use of social networking tools among Lebanese students Global Journal of Information Technology: Emerging Technologies. 7(1), 196-205

Table 2 Comparison between the purposes of various SN uses

\begin{tabular}{|c|c|c|c|c|c|}
\hline & WhatsApp & Facebook & Email & Blog & Wiki \\
\hline $\begin{array}{l}\text { Communicate with family \& } \\
\text { friends }\end{array}$ & $100 \%$ & $100 \%$ & $100 \%$ & - & - \\
\hline Make social contacts & $\overline{90 \%}$ & $\overline{100 \%}$ & $54 \%$ & $8 \%$ & $6 \%$ \\
\hline Text chat & $\overline{100 \%}$ & $\overline{100 \%}$ & - & - & - \\
\hline Self-promotion / self-marketing & $\overline{40 \%}$ & $\overline{44 \%}$ & $70 \%$ & $0 \%$ & $0 \%$ \\
\hline Education/ self-learning & $50 \%$ & $40 \%$ & $40 \%$ & $57 \%$ & $58 \%$ \\
\hline Entertainment & $60 \%$ & $54 \%$ & $14 \%$ & - & - \\
\hline Text/picture/ audio/video sharing & $100 \%$ & $\underline{90 \%}$ & $14 \%$ & - & - \\
\hline Group collaboration & $\overline{70 \%}$ & $\overline{70 \%}$ & - & $70 \%$ & $75 \%$ \\
\hline Ideas and information sharing & $100 \%$ & $66 \%$ & - & $36 \%$ & $38 \%$ \\
\hline Group study / problem solving & $\overline{100 \%}$ & $100 \%$ & $8 \%$ & - & - \\
\hline $\begin{array}{l}\text { Online journaling/personal } \\
\text { blogging }\end{array}$ & $=$ & $=$ & - & $10 \%$ & $5 \%$ \\
\hline Shared editing & $=$ & $=$ & - & $50 \%$ & $60 \%$ \\
\hline
\end{tabular}

Survey Question: For what ends do you use the following SN tools the most? (Choose as many as you like)

\subsubsection{Qualitative Research Findings: Results from the Focus Group Interviews}

During the focus group interviews, the students declared having a class Facebook page for daily collaboration on homework and discussion about difficult lessons. They also used the Facebook page to post classwork for absent students and revision sheets before tests. In addition, some students had a group with their close friends on WhatsApp, to share learning materials, complemented by the use of Voice-over IP applications, such as Skype, Viber or Tango. Moreover, students said in the interviews that some high achievers were very helpful, active and popular online.

When asked about the disadvantages of these tools, all the students agreed that these SN tools might be a waste of time, if overused, and may hinder their learning, if not controlled. "Time limit has to be set for their uses. I was not sitting anymore with my family", claimed a student in the interview. Another one said, "My parents were not happy to see me on the computer all the time." Selfregulation and responsible use of these tools were critical issues to be maintained (Zein, 2014). It could be argued that this social aspect might be a distraction for the students' learning. However, Rovai (2002) suggested that, within a learning community, students need to feel connected to each other and it may be that the virtual 'chat' that occurred helped the students develop a sense of acceptance, belonging and recognition, as part of the learning community. This sense of belonging to a learning community and an equal democratic voice appeared in a student's comment during the interview when she answered, "These tools gave us extra communication with all the class students at the same level, whereas normally I communicate only with my close friends. Sometimes I wished to communicate with some classmates but I did not want to be seen as running behind them. It opened all the class students to each other; it tightened the students' belonging to the class." Another student mentioned that a minimum positive face-to-face encounter with his teacher and students in the classroom is a prerequisite for effective online communication.

According to students, SN communication facilitated informal discussion and learning, anytime and anywhere. A student said, "You need to be connected and you can chat, socialize, share pictures, videos, audios at night or during the day wherever you are, very easily and quickly. It is amazing!" Communication is not only limited to text messages; it can be done with picture, video or audio messages, which makes it more attractive, practical and real. Moreover, a student said that these tools were advantageous for shy students who usually fear talking publicly in class. Zemsky and Massy (2004) argued that the aspects of SN for entertainment, social interaction and communication seemed much more interesting to students than the more traditional educational approaches. Vaidhyanathan 
(2008) also declared that students use SN tools, such as MySpace and Facebook, for their ease, socialization and fun aspects, rather than because they are learning tools. During the interview, a student claimed that, "The affordable cost of these technologies is encouraging us to use them. We don't need to ask for money from our parents". The low cost and easy use of various communication means might explain the students' motivation behind their extensive utilization.

In the focus group interview, a student noted that only Blogs and Wikis were used most in formal learning because teachers were utilizing them in class. Moreover, SN tools support collaborative activities, which allow for knowledge sharing and communicating, reflection and debate (Hiler, 2002; Zein, 2015b). During the focus group interview, when asked to comment on the type of collaboration, a student said, "I like to share my work with my friends and to have their feedback. My friends corrected my mistakes before my teacher saw my answers. They helped me a lot. It is good to work in groups to solve our homework or do a group assignment."

As noted, these three most-used tools emphasized informal learning through collaboration, group work, sharing information and, most importantly, the independent learning issue. However, communication and socialization represented the most targeted activities, compared to the formal and informal learning ones.

When asked during the focus group interviews, the reasons behind the popularity of WhatsApp over the remaining SN tools as shown in the quantitative data analysis, the answers were as follows:

(1) the ease of use, because it does not need a username and password, like Facebook, Email, Blog and Wiki; (2) the ease in manipulating and creating text/audio/video/picture messages; (3) its low cost; it is sufficient to have an Internet connection on your mobile; (4) its interface is more adapted to cell-phones than all the other tools; (5) its mobility; WhatsApp is available on a cell-phone, carried anywhere by students all day; (this is not the case where the other devices, such as tablets, laptops and desktops, are needed); (6) WhatsApp introduced free telephone calls, thus overpassing Skype, Viber, Tango and any voice-over IP applications found in the Lebanese market; (7) historically speaking, WhatsApp appeared in the Lebanese market before Viber and Tango so people are acquainted with using it and most of the students are satisfied with it; (8)until now, Skype, Viber and Tango do not have better features.

The main disadvantages of using WhatsApp were: (1) impracticality at editing messages; (2) the sequential appearance of messages and an inability to organize and archive information in an effective manner, to be utilized later on; (3) difficulties in reading or manipulating large text messages or files; however, very practical in displaying, using or creating video or audio files; (5) lack of ownership, as you can only see the last sender of the message.

As a conclusion, students were found to be motivated and using SN tools extensively, for both socializing and informal learning whilst only Email, Blog and Wiki were used for formal learning, in a limited way, because teachers were using these tools in class. The ease of technology, the variety of means (text/audio/video), the practicality (anywhere, anytime), and the low cost, were behind this extensive use. Moreover, the popularity of WhatsApp Messenger has increased over all the other SN tools, for reasons such as ease of use, practicality and mobility.

\subsection{Research Question (2): "What are the students' preferences for SN uses in the learning process?"}

The data collected from the questionnaire and the focus group interview showed the preferences for these tools regarding various learning tasks, which are: revision of lectures online; online study group discussion; submission of group assignments; online class discussion with the teacher; online individual learning discussion with a classmate and receiving assignments online from the teacher. 


\subsubsection{Quantitative Research Findings: Results from the Survey Questionnaire}

The survey asked the students for their preferences in multiple learning tasks. The scale used for their choice preferences ranged from 1 , for the mostly preferred, to 6 , for the least preferred. The preference numbers were added for the 125 students' answers, thus the smallest sum showed the higher preferences for the students, whilst the largest value showed the lower preferences.

Table 3 Students' preferences for the revision of lectures online

\begin{tabular}{lll}
\hline Item & Total & Order \\
\hline Watching Vodcast (video) of the lecture & 365 & 1 \\
Listening to Podcast (audio) of the lecture & 392 & 2 \\
Going through the lecture slides & 410 & 3 \\
Talking to my peers on Skype & 417 & 4 \\
Discussing it with my peers using text chat on & 487 & 5 \\
IM & & \\
Discussing it on the unit blog & 592 & 6 \\
\hline
\end{tabular}

Survey Question: I prefer to revise lecture online using ...

Table 3 indicates that the highest preferences of the students for revising a lecture was through Vodcast, 365, closely followed by Podcast, 392, whilst Blog showed the least preference, 592.

Table 4 Students' preferences for online group study discussion

\begin{tabular}{lll}
\hline & Total & Order \\
\hline audio conference & 440 & 4 \\
video conference & 535 & 5 \\
Email & 552 & 6 \\
IM & 380 & 3 \\
Blog/wiki & 365 & 2 \\
Facebook & 352 & 1 \\
\hline
\end{tabular}

Survey Question: I prefer to have online group study discussion through ....

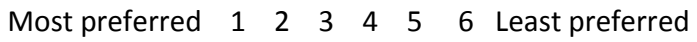

In Table 4, the sentence, "I prefer to have an online group study discussion through..." had a total value of 352 for Facebook, closely followed by a total of 365 for Blogs and Wikis, and 380 for IM. This presented the importance of Facebook, Blog, Wiki and IM as communication tools, with classmates having a group discussion. Email had the lowest preference in online group discussion. This emphasizes the many-to-many forms of communication.

Table 5 Students' preferences in submitting group assignments to teacher

\begin{tabular}{lll}
\hline & Total & Order \\
\hline as a Podcast presentation & 455 & 5 \\
as a Vodcast presentation & 427 & 3 \\
\hline
\end{tabular}


Zein, R., Lababidi, H. \& Dimashkieh, M. (2017). Exploring the use of social networking tools among Lebanese students Global Journal of Information Technology: Emerging Technologies. 7(1), 196-205

\begin{tabular}{lll}
\hline through Email & 445 & 4 \\
through unit Blog or Wiki & 370 & 1 \\
through IM & 542 & 6 \\
through Facebook & 377 & 2 \\
\hline
\end{tabular}

Survey Question: I prefer to submit online a group assignment to a teacher using .... Most preferred $1 \begin{array}{llllllll} & 2 & 3 & 4 & 5 & 6 & \text { Least preferred }\end{array}$

When observing Table 5 from the survey, Blog and Wiki were found to have the highest preferences between the selected SN tools for submitting online group assignments to the teachers, with a total of 370 points. Facebook came next, with a total of 377 . This indicates the students' preferences for group assignment submissions to the teachers through these tools. This emphasized the close educational preference between Facebook and Blog/Wiki for group work submission.

Tables 4 and 5 showed Facebook, Blog and Wiki had the highest preferences between the selected SN tools. This fact highlighted that many-to-many communication was mostly present in study group work and collaboration. Additionally, these tables indicated that Email, Podcast and Vodcast have a potential in collaboration and group work, whereas IM presented the lowest preference for group work activities, where students have to collaborate on a common learning task.

Table 6 Students' preferences for an online class discussion with the teacher

\begin{tabular}{lcc}
\hline & Total & Order \\
\hline audio conference & 382 & 2 \\
video conference & 367 & 1 \\
Email & 540 & 6 \\
IM & 437 & 4 \\
Blog/Wiki & 425 & 3 \\
Facebook & 465 & 5
\end{tabular}

Survey Question: I prefer to have an online class discussion with the teacher through...

$\begin{array}{llllllll}\text { Most preferred } & 1 & 2 & 3 & 4 & 5 & 6 & \text { Least preferred }\end{array}$

Table 7 Students preferences for an online learning discussion with a classmate

\begin{tabular}{lcc}
\hline & Total & Order \\
\hline audio conference & 370 & 2
\end{tabular}

Survey Question: I prefer to have an online learning discussion with a classmate through Most preferred $11 \quad 2 \quad 3 \quad 4 \quad 5 \quad 6 \quad 6$ Least preferred

Observing Tables 6 and 7, video conferencing had the highest preference for "I prefer to have an online class discussion with the teacher through..." and "I prefer to have an online learning discussion with a classmate through..." with, respectively, 367 and 347, whilst audio conferencing had 382 and 370 , respectively, for the same learning tasks. The first learning task emphasized one-to-many 
communication, whilst the second one emphasized one-to-one communication. However, Email and Facebook, in Tables 6 and 7 were found to have the lowest preferences for the last two learning activities.

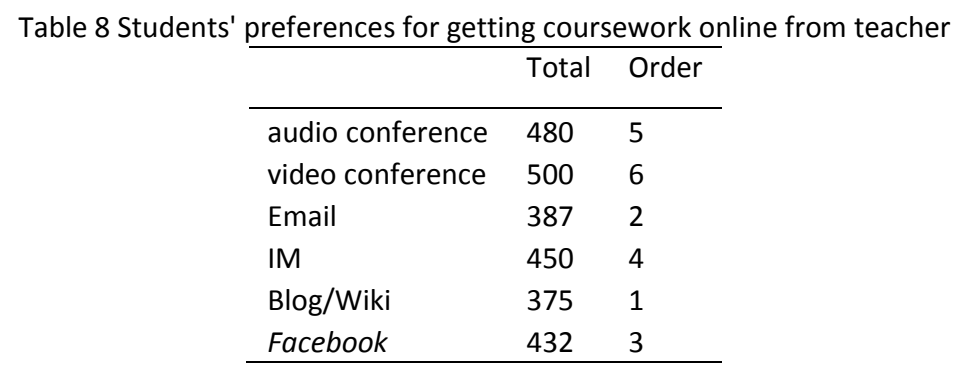

Survey question: I prefer to get coursework online from the teacher through...

Most preferred $1 \begin{array}{llllllll} & 2 & 3 & 4 & 5 & 6 & \text { Least preferred }\end{array}$

In addition, the students gave Blog/Wiki 375 and Email 387, which are the highest preferences in Table 8, as a way to receive assignments online from the teacher or as one-to-many communication.

\subsubsection{Qualitative Research Findings: Results from the Focus Group Interviews}

During the focus group interview, when asked about the reasons why the students preferred Vodcast/Podcast for revising a lecture (Table 3), they said that they were audio recording or videotaping teachers' lectures, or taking photos of the blackboard, after getting their teacher's approval.

Facebook was more popular than IM for online group study discussion (Table 4) because, as a student explained in the focus group interview, "Facebook is more practical than IM in managing or sharing large files or messages".

When the researcher questioned about the motivation behind the preference for submitting a group assignment online to the teacher (Table 5), a student clarified, 'We can have a full archiving of the different stages of the assignment easily manageable which is not found in other SN tools. Moreover, we know who did what in the assignment'. Another student said that, 'Student contribution is shown individually. So, if a student did not contribute, he or she will not have any posts. This public posting was motivating students to work."

Furthermore, when asked about their preferences on submitting a group assignment online to the teacher through Blog and Wiki (Table 5), some students claimed that Blog and Wiki's environment does not involve a student's personal life; therefore, it's less distracting and educationally more focused than Facebook.

A student explained that Blog and Wiki are better than IM in editing messages; "Modifying large information is not very practical with IM". Technical limitations in the features might hinder the use of certain $\mathrm{SN}$ tools, at the expense of other ones.

During the group interview, a student explained that video and audio conferencing are more interactive because you can see and/or listen to your interlocutor when having an online class discussion with the teacher (Table 6) or having an online learning discussion with a classmate (Table 7). He said, "You can see the facial expression and the reaction of your interlocutor. This issue is not present in text communication as Email, Facebook, Blog and Wiki." Students suggested during the interview that, although they prefer Facebook for many learning tasks, it has an inconvenience; their 
private life, their friendship and their social relationships are interfering with their learning, therefore, it is a source of distraction. Students have to be responsible and self-regulated in the online environment. During the interview, the students raised another concern. They might criticize their teachers on their Facebook class page. Adding their teacher or a school representative onto their SN page might limit their freedom of expression.

Both audio conference 480 and video conference 500 got the lowest preference for receiving coursework online from the teacher (Table 8). A student claimed in the interview that they preferred to have printed assignments, rather than audio or video ones. Another student suggested that they had never thought of having an assignment on video or audio and he might be interested in receiving assignments in audio or video formats. Finally, IM 450 was found to have a moderate value in getting coursework online, due to a practicality issue, as one student explained, "WhatsApp screen is small for reading or editing large information".

Triangulating data from focus group interviews and surveys clearly shows the high potential of these SN tools as useful for anyplace, anytime collaboration, as one-to-one, one-to-many and, notably, many-to-many communication channels for both formal and informal learning. Students showed a preference for multimedia communications over texting ones. However, the negative impact of 
Zein, R., Lababidi, H. \& Dimashkieh, M. (2017). Exploring the use of social networking tools among Lebanese students Global Journal of Information Technology: Emerging Technologies. 7(1), 196-205

Rovai, A. P. (2002). Sense of community, perceived cognitive learning, and persistence in asynchronous learning networks. The Internet and Higher Education, 5(4), 319-332.

Saeed, N., \& Yang, Y.(2008). Incorporating blogs, social bookmarks, and podcasts into unit teaching. Retrieved on $10^{\text {th }}$ January, 2009 from http://www.ict.swin.edu.au/personal/yvang/Publications.html

Solomon, G., \& Schrum, L.(2007). Web 2.0: New tools, new schools. Washington, DC: International Society for Technology in Education.

Vaidhyanathan, S. (2008). Generational myth. The Chronicle of Higher Education, 55(4).

Zein, R. (2014). Explorative study on the ways of using Blogs and Wikis as teaching and learning tools in mathematics. In M. Searson \& M. Ochoa (Eds.), Proceedings of Society for Information Technology \& Teacher Education International Conference, 2014, Jacksonville, Florida (pp. 66-72). Chesapeake, VA: Association for the Advancement of Computing in Education (AACE).

Zein, R. (2015a). How Do Blogs and Wikis Support Social Constructivist Learning in Math. Global Learn, 2015(1), 18-27.

Zein, R. (2015b). Literature Review on Web 2.0 Conceptual Framework and Characteristics. In Global Learn, 2015(1), 612-621

Zein, R., \& Majdalani, M. (2012). Implementation of blogs and wikis in a middle school math class: An exploratory case study. In Society for Information Technology \& Teacher Education International Conference, 2012(1), 3177-3182

Zemsky, R., \& Massy, W. F. (2004). Thwarted innovation: What happened to e-learning and why. Retrieved from; http://www.irhe.upenn.edu/Docs/Jun2004/ThwartedInnovation.pdf 